\title{
Effect of non-associated electrolyte solutions on the behaviour of poly(vinyl alcohol)-based hydrogels
}

\author{
Silvia Patachia ${ }^{\mathrm{a}, *}$, Artur J.M. Valente ${ }^{\mathrm{b}}$, Claudia Baciu ${ }^{\mathrm{a}}$ \\ a Department of Chemistry, "Transilvania" University of Brasov, 29 Eroilor Street, 500036 Braşov, Romania \\ b Department of Chemistry, University of Coimbra, 3004-535 Coimbra, Portugal
}

Received 25 July 2006; received in revised form 6 November 2006; accepted 8 November 2006

Available online 20 December 2006

\begin{abstract}
The aim of this paper is to present the behaviour of the poly(vinyl alcohol) hydrogels [PVA-HG] in sodium and potassium chlorides aqueous solutions, due to their interactions. The tested [PVA-HG]-s have been obtained by repeated freezing and thawing cycles. White, heterogeneous hydrogels have been obtained. These hydrogels exhibit a mechanical active behaviour at their contact with electrolytes aqueous solutions, manifested by important changing in mass, volume and density of the hydrogel samples. These modifications could be explained by water elimination from the hydrogels that initially reached the equilibrium of swelling. The kinetic of the water desorption and the reversibility of this process, have been studied and some of the factors that influence this behaviour have been evidenced. The sensitivity of PVA hydrogels to electrolyte nature and concentration could be used in sensors design and also could explain some aspects of electrolytes diffusion through PVA membranes and targeted drugs delivery.
\end{abstract}

(C) 2006 Elsevier Ltd. All rights reserved.

Keywords: Poly(vinyl alcohol); Hydrogel; Electrolytes; Swelling; Collapse

\section{Introduction}

Hydrogels are polymeric materials with a threedimensional structure that exhibit the ability to swell in water and retain a significant fraction of water within their structures. It is well known that the swelling behavior of polymer gels depends on their network structure whereas the latter is closely related to the conditions under which the polymer gels are formed (e.g. [1]). Some of them, generally

\footnotetext{
* Corresponding author. Tel.: +40 741649792; fax: +40 26841 0525 .

E-mail address: st.patachia@unitbv.ro (S. Patachia).
}

obtained from hydrophilic monomers [2], are "conventional" in that they do not exhibit any significant volume transition to environmental changes $(\mathrm{pH}$, temperature, etc.), while others, so-called "intelligent" hydrogels, can change their volumes abruptly in response to the changes of the external environmental factors, such as temperature [3-6], pH [6], photo field [7], ion concentration [8], composition of the solvent [9], etc.

Poly(vinyl alcohol) [PVA] is a well-known polymer, which can generate hydrogels by physical or chemical crosslinking [10-16,37-43]. PVA has been used to develop new materials for different areas such as intelligent polymers [17-20], medicine [21], 
drug release [22-42], sensors [43], cell encapsulation material [15], etc. One important feature of PVA hydrogels [PVA-HG] is the ability to change their mass, volume and density in contact with electrolyte solutions by eliminating a certain quantity of water which was firstly retained by the hydrogel $[12,14]$. The present paper shows the effect of non-associated electrolyte solutions $(\mathrm{NaCl}$ and $\mathrm{KCl}$ ) on the swelling behaviour of poly(vinyl alcohol)-based hydrogels prepared by repetitive freezing and thawing cycles. Two reasons have been taken in to account when we have chosen for a physical method of hydrogel obtaining. The first one is related to avoiding the presence of other substances in the hydrogel system, like non-reacted crosslinker or traces of initiator and catalyst. In this way the influence of $\mathrm{Na}^{+}$and $\mathrm{K}^{+}$ ions on the hydrogels behaviour could be well characterized. The second reason is related with the very large medical applications of the PVA hydrogels obtained by freezing and thawing method. The body fluids contain $\mathrm{Na}^{+}$and $\mathrm{K}^{+}$ions and as consequence, it is very important to have information related with the behaviour of PVA hydrogels in the presence of these ions.

Kinetics of sorption of water in/from hydrogel and the transformation in shape and volume modifications of the sample according to the concentration of the immersion solution, of the time and of the cation nature, are also presented. Taking into account the large applications of the PVA-HG in medicine, drugs industry, agriculture, environmental protection, these studies could be helpful to explain the behaviour of the mentioned gel in the presence of different salts, the influence of the salts on the gel morphology and consequently on its capacity to retain water, to be loaded with different electrolytes, or on the permittivity against different substances (i.e. drugs, fertilizers, insecticides, etc.).

\section{Experimental}

\subsection{Materials}

(A) The PVA hydrogel has been obtained from PVA 90-98 (polymerization degree 900, hydrolyze degree 98\%) supplied from The Chemical Plant Râşnov, industrial grades and it was used without further purification.

The PVA powder was solved into magnetically stirred distilled water for $3 \mathrm{~h}$ at $80^{\circ} \mathrm{C}$ getting a solution with the concentration in solid matter (CS) by
$11.14 \%$. The solution obtained in this way was cooled and introduced in PVC cylindrical containers having a diameter of $d=1.80 \mathrm{~cm}$. Then the solution was submitted at three successive freezing (at $-15^{\circ} \mathrm{C}$ ) and defreezing cycles (at room temperature), each stage lasting $12 \mathrm{~h}$. After that, we got a hydrogel with a good mechanical resistance, white and opaque, which proves a heterogeneous structure.

(B) Potassium and sodium chlorides, commercially available ("Reactivul" Bucuresti), pro-analysis grade have been used. $\mathrm{KCl}$ and $\mathrm{NaCl}$ solutions ( $1 \mathrm{M}, 2 \mathrm{M}$ and $3 \mathrm{M}$ ) were prepared from the solid state using distilled water.

\subsection{Methods of study}

\subsubsection{The study of the desorption equilibrium}

It has been used two types of samples (some, named type I with $c a$. $0.03-0.06 \mathrm{~g}$ and others, named type II, with mass around 1.1-2.2 g) prevailed from the hydrogel mass and immersed in distilled water until equilibrium is reached (14 days).

To study the phenomenon of water desorption from swollen hydrogels in electrolyte solutions presence, each sample was immersed into $20 \mathrm{~mL}$ (for small samples) and $30 \mathrm{~mL}$ (for big samples) respectively, of electrolyte solution, at different concentrations $1 \mathrm{M}, 2 \mathrm{M}$ and $3 \mathrm{M}$. The samples were taken from time to time and weighed with an analytical balance with a precision of $0.1 \mathrm{mg}$. The mass variation was recorded as a function of time.

The water desorption has been expressed by the percent of water kept into the hydrogel mass $\left(\Delta m_{\mathrm{w} t}\right)$ at the time $t$ after hydrogel immersion in electrolyte solution, and calculated by using the following formula:

$$
\Delta m_{\mathrm{w} t}(\%)=\frac{m_{\mathrm{w} t}-m_{\mathrm{x}}}{m_{\mathrm{we}}-m_{\mathrm{x}}} \times 100
$$

where $m_{\mathrm{we}}$ is the equilibrium mass of the swollen hydrogel in water and $m_{\mathrm{x}}$ is the mass of the xerogel.

The hydrogel collapse has been expressed by normalized collapse degree (NCD) calculated as follows:

$\mathrm{NCD}_{t}=\frac{m_{\mathrm{we}}}{m_{\mathrm{s} t}}$

where $m_{\mathrm{we}}$ is the hydrogel mass at its equilibrium of swelling and $m_{\mathrm{s} t}$ is the hydrogel mass at time $t$ after immersing in salt solution. 


\subsection{Experimental data: discussions}

Fig. 1 shows the effect of the electrolyte concentration on the mass of hydrogel samples as a function of the time. It can be observed that in the presence of both electrolytes $(\mathrm{NaCl}$ and $\mathrm{KCl})$ aqueous solution the hydrogel samples diminish their mass.

Such behavior can be due to elimination of a certain quantity of water, working the hydrogel as an osmotic pump. After $500 \mathrm{~min}$ the water mass eliminations become smaller, till approximately $1500 \mathrm{~min}$, at equilibrium state.

Once the salts concentration increases it can see an increasing loss of mass reaching to the following situation: when immersing into $3 \mathrm{M}$ solution the sample loses by $40 \%$ from its water content. This fact reveals the PVA hydrogel special sensitivity in the presence of electrolytes. The last ones determine the modification of the balance between the interactions of the species present in the system: waterpolymer; polymer-polymer, water-electrolyte and polymer-electrolyte. In the presence of electrolyte solutions, PVA intramolecular interactions increase and the collapse occurs.

To check the influence of the hydrogel samples dimensions on the desorption phenomenon, both types of hydrogel samples have been tested (type I and type II). As it can be seen in Fig. 2, the influence of hydrogel dimensions on its final mass decreasing can be neglected, especially for solutions with higher concentration.

Although the swelling equilibrium of hydrogels is not influenced in a determinant way by the samples

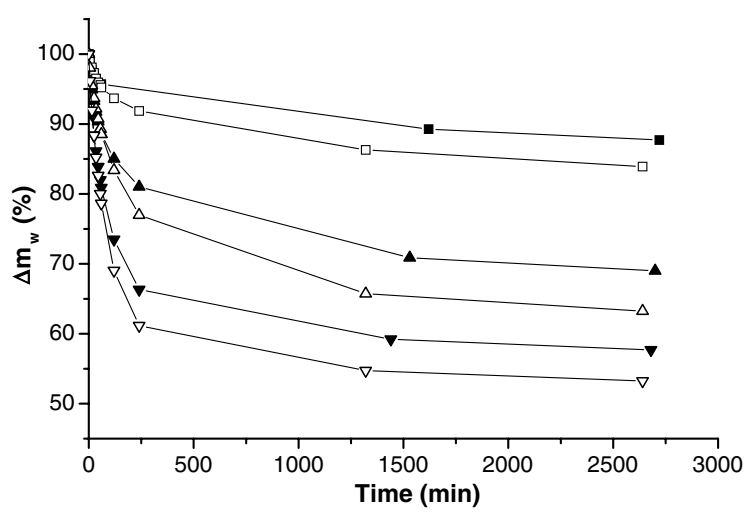

Fig. 1. Percent of the retained water variation as a function of time and of the electrolyte nature and concentration: $(\mathbf{\square}) \mathrm{NaCl}$

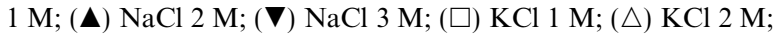
( $\nabla) \mathrm{KCl} 3 \mathrm{M}$.

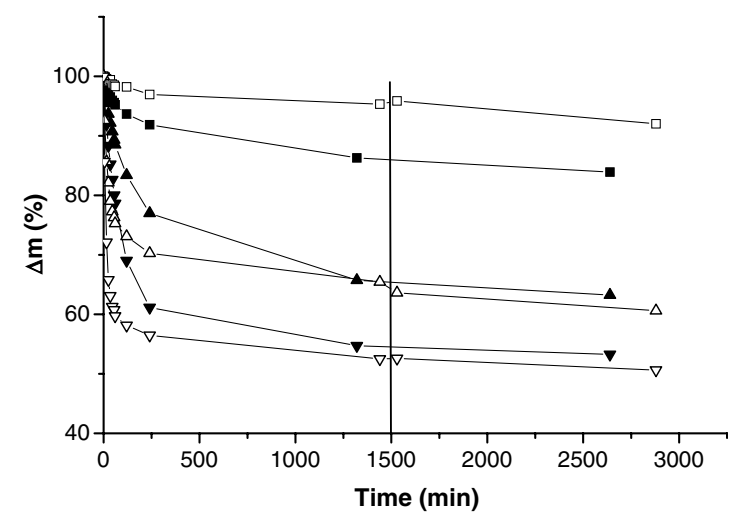

Fig. 2. The influence of the hydrogel samples dimensions on the water desorption: sample type I: $(\square) \mathrm{KCl} 1 \mathrm{M} ;(\triangle) \mathrm{KCl} 2 \mathrm{M} ;(\nabla)$ $\mathrm{KCl} 3 \mathrm{M}$ and type II: (口) KCl $1 \mathrm{M} ;(\boldsymbol{\Delta}) \mathrm{KCl} 2 \mathrm{M}$; ( $) \mathrm{KCl} 3 \mathrm{M}$.

dimension, the kinetic of water desorption from hydrogels are strongly influenced by this factor (see Fig. 3).

From Fig. 3 it can be seen that the elimination of water from hydrogels (des-swelling) is strongly influenced by the initial minutes of the contact between the hydrogels and electrolytes solution. The hydrogels water desorption rate increases when the electrolyte solution concentration increases and when the hydrogel dimensions are lower.

Table 1 contains the fitting parameters, as a linear dependency, of the water mass retained in hydrogel, after its immersion in different types of electrolytes solutions as a function of time.

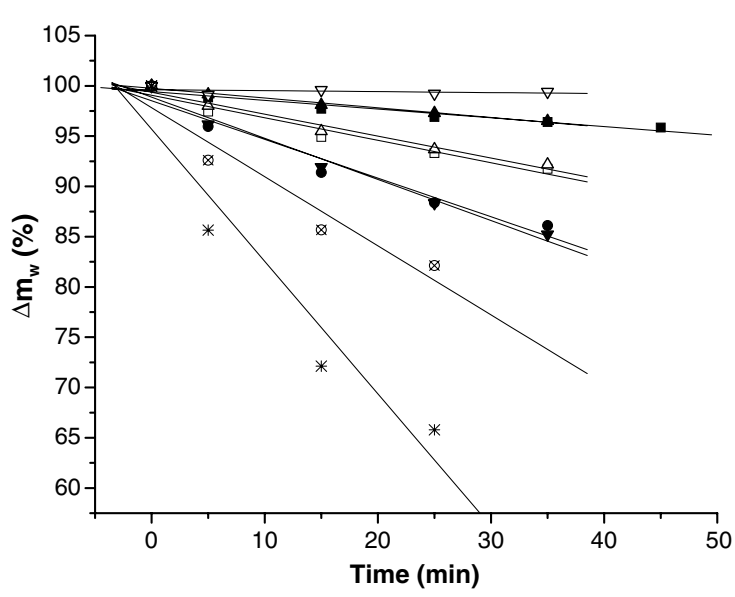

Fig. 3. Water mass retained in hydrogel, after its immersion in different types of electrolytes solutions with different concentra-

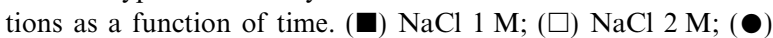
$\mathrm{NaCl} 3 \mathrm{M}$. Samples type I: $(\nabla) \mathrm{KCl} 1 \mathrm{M} ;(\otimes) \mathrm{KCl} 2 \mathrm{M}$; (*) $\mathrm{KCl}$ $3 \mathrm{M}$; and type II: $(\Delta) \mathrm{KCl} 1 \mathrm{M} ;(\triangle) \mathrm{KCl} 2 \mathrm{M}$; ( $) \mathrm{KCl} 3 \mathrm{M}$. 
Table 1

Fitting parameters, as a linear dependency, of the water mass retained in hydrogel, after its immersion in different types of electrolytes solutions as a function of time

\begin{tabular}{|c|c|c|c|c|c|c|}
\hline Crt. Nr. & Hydrogel mass (g) & Electrolyte type & Solution concentration $(\mathrm{M})$ & $a(\%)$ & $b(\% / \mathrm{min})$ & $R^{2}$ \\
\hline 1 & $1.1-1.9$ & $\mathrm{NaCl}$ & 1 & 99.4342 & -0.0870 & 0.9694 \\
\hline 2 & & & 2 & 99.0671 & -0.2239 & 0.9759 \\
\hline 3 & & & 3 & 98.5208 & -0.3845 & 0.9767 \\
\hline 4 & $1.3-2.2$ & $\mathrm{KCl}$ & 1 & 99.7592 & -0.0968 & 0.9911 \\
\hline 5 & & & 2 & 99.3694 & -0.218 & 0.9863 \\
\hline 6 & & & 3 & 98.8815 & -0.4092 & 0.9897 \\
\hline 7 & $0.03-0.06$ & $\mathrm{KCl}$ & 1 & 99.623 & -0.0096 & 0.9980 \\
\hline 8 & & & 2 & 97.8325 & -0.6865 & 0.9634 \\
\hline 9 & & & 3 & 95.6965 & -1.3161 & 0.9600 \\
\hline
\end{tabular}

Fig. 4 shows the decreasing of hydrogel water content as a function of the electrolyte concentration, in the case of type II hydrogel samples, at a pre-established time (1500 $\mathrm{min})$. The retained water level in PVA-HG-s initially immersed in $\mathrm{KCl}$ solutions is lower than that retained in PVA-HG-s immersed in $\mathrm{NaCl}$ solutions. This behaviour evidences higher interactions between PVA-HG-s and $\mathrm{KCl}$ and as consequence their higher collapse. Such behaviour can be directly related with the breaker effect on the water structure provoked by $\mathrm{K}^{+}$and, consequently, the polar sites of PVA becomes more accessible to interact with the electrolyte.

From Fig. 5 it can be seen that the use of NCD as indicator of the behaviour of PVA-HG in the presence of electrolytes solutions is more sensitive than the use of water percentage retained by hydrogel. So, NCD shows that PVA hydrogels are more sen-

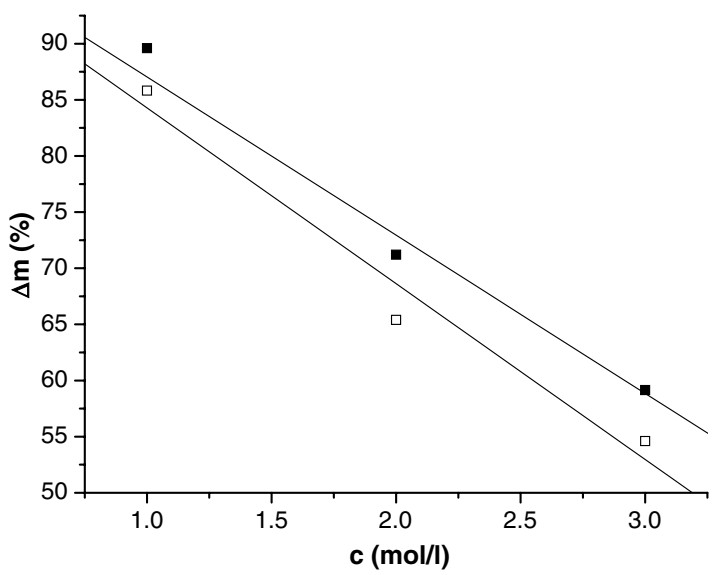

Fig. 4. The water mass retained in hydrogels after its immersion in different types of electrolyte solutions as a function of solution concentration: $(\boldsymbol{\square}) \mathrm{NaCl}$; $(\square) \mathrm{KCl}$.

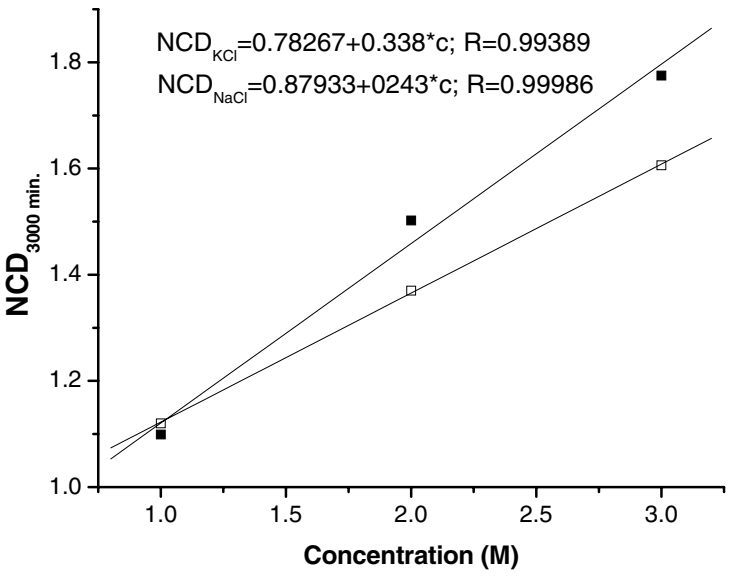

Fig. 5. Hydrogels NCD as function of electrolyte nature and its concentration in solution of hydrogel immersion: $(\square) \mathrm{NaCl}$; $\mathrm{KCl}$.

sitive to the nature of electrolyte at higher electrolyte solution concentration.

Analyzing the water diffusion process, accordingly with the following relation:

$1-\frac{M_{\mathrm{w} t}}{M_{\mathrm{we}}}=B t^{n}$

where $M_{\mathrm{w} t}$ and $M_{\mathrm{we}}$ are the mass of samples at time $t$ and at equilibrium time, respectively, and $B$ is a constant, we can conclude from the obtained values for $n$ (between 0.5 and 1) (Fig. 6), that the mechanism of diffusion is non-Fickian. The values of $n$ obtained for water diffusion from the PVA hydrogel, in the presence of $\mathrm{KCl}$ are higher than these obtained for diffusion in the presence of $\mathrm{NaCl}$. Also the values of $n$ are strongly dependent on the $\mathrm{KCl}$ solutions concentrations, but seem to be quite 


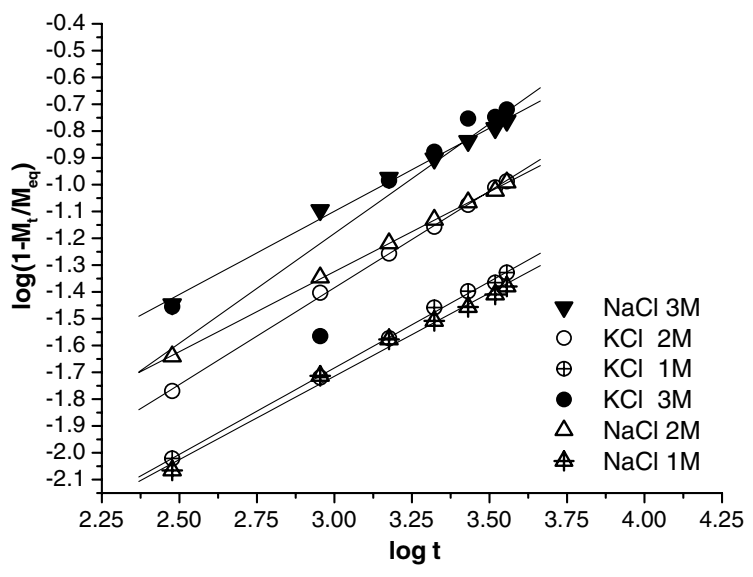

Fig. 6. Determination of the values for $n$, characterizing water diffusion from PVA hydrogels in the presence of $\mathrm{NaCl}$ and $\mathrm{KCl}$ solutions having different concentrations.

independently on the $\mathrm{NaCl}$ solution concentration (Table 2).

Probably, the higher concentration of $\mathrm{K}^{+}$ions determines the destroying of a higher amount of $\mathrm{H}$ bonds between $\mathrm{OH}$ groups of PVA and water molecules and as consequence, the polymer chains become more mobile and could restructure them during the diffusant redistribution in the polymer matrix. $\mathrm{Na}^{+}$ ions have no the capacity of $\mathrm{H}$-bonds cracker and so, the H-bonds borned between polymer and water molecules maintain the same structure of gel, independently on $\mathrm{Na}^{+}$ions concentration. It could be assumed that $\mathrm{K}^{+}$ions influence more the bonded and weakly bonded water molecules while the $\mathrm{Na}^{+}$ ions influence more the free water molecules from the hydrogel structure.

As consequence, the diffusion of water from the PVA swollen gel in the presence of studied electrolytes aqueous solutions seems to be better described by the Fickian model in the presence of $\mathrm{NaCl}$ and closer to molecular relaxation model in the presence of $\mathrm{KCl}$.

Table 2

$n$ Values for water diffusion from PVA hydrogels in the presence of $\mathrm{NaCl}$ and $\mathrm{KCl}$ solutions having different concentrations

\begin{tabular}{lllll}
\hline $\begin{array}{l}\text { Crt. } \\
\mathrm{Nr} .\end{array}$ & $\begin{array}{l}\text { Electrolyte } \\
\text { type }\end{array}$ & $\begin{array}{l}\text { Electrolyte solution } \\
\text { concentration }(\mathrm{M})\end{array}$ & $n$ & $R^{2}$ \\
\hline 1 & $\mathrm{KCl}$ & 3 & 0.818 & 0.890 \\
2 & $\mathrm{KCl}$ & 2 & 0.721 & 0.9996 \\
3 & $\mathrm{KCl}$ & 1 & 0.644 & 0.9990 \\
4 & $\mathrm{NaCl}$ & 3 & 0.620 & 0.9970 \\
5 & $\mathrm{NaCl}$ & 2 & 0.600 & 0.9998 \\
6 & $\mathrm{NaCl}$ & 1 & 0.621 & 0.9957 \\
\hline
\end{tabular}

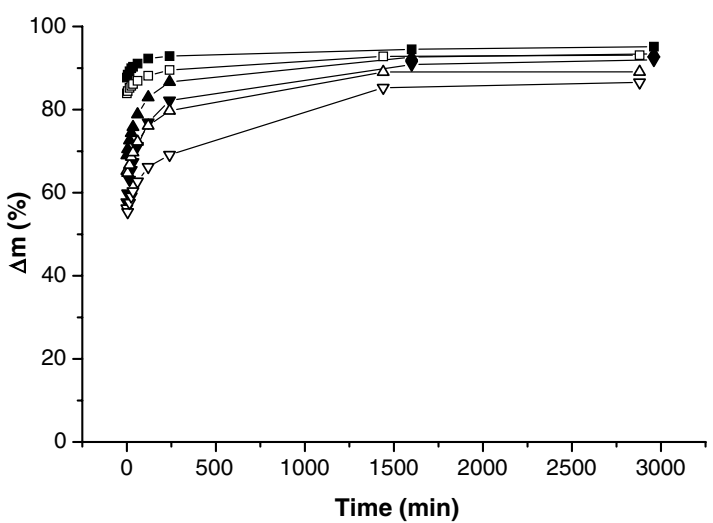

Fig. 7. The variation of the re-swollen hydrogels weight at their re-immersion in water as a function of time: $(\boldsymbol{\square}) \mathrm{NaCl} 1 \mathrm{M}$; $(\boldsymbol{\Delta})$

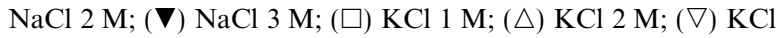
$3 \mathrm{M}$.

In Fig. 7 we illustrated the coming back of the initially swell balance, after the immersion into distilled water of the shrunk samples under the influence of the electrolytes. It can be observed that the shrunk samples reabsorb water, evidenced by the increasing of their mass until they reach to equilibrium. This behaviour does not depend on the nature of the electrolyte in which the samples were initially immersed for contracting.

In conclusion, both $\mathrm{NaCl}$ and $\mathrm{KCl}$ case the coming back to the initial balance of swelling is not total.

Comparing the results obtained we draw to the conclusion that in the sample immersed into $\mathrm{NaCl}$ solution case, the recovery to the initial equilibrium state was at a smaller difference of $8 \%$ while in the samples immersed into $\mathrm{KCl}$ solutions the difference between the initial and the coming back stage was approximately $15 \%$. This can be explained by the fact that $\mathrm{KCl}$ is well known for being able to break up the $\mathrm{H}$ bonds between the systems components [16]. So, that can break up the $\mathrm{H}$ bonds between the $\mathrm{H}_{2} \mathrm{O}$ molecules and the polymer molecules, producing a more powerful interaction between these ions $\left(\mathrm{K}^{+}\right)$and the PVA macromolecule. The $\mathrm{Na}^{+}$ cations interact less with the polymer already involved in $\mathrm{H}$ bonds with $\mathrm{H}_{2} \mathrm{O}$ molecules, so it is less kept into the hydrogel structure.

Re-immersing the samples into the water, the quantity of electrolyte kept into hydrogel structure will diffuse into water. The more concentrated the electrolyte solution will be obtained when diffusing them into the water, the more the quantity of kept in ions was bigger. 
This solution will determine the maintenance of the hydrogel into the contracted state, not permitting to it in the coming back to the initial equilibrium swelling state.

Determining the concentration of the solutions obtained by re-immersing the shrunk hydrogels in distilled water, by interpolation the percentage of water retained in HG-s on the HG-s collapse curve from the Fig. 8, we obtained the values shown in Table 3.

As it could be seen, PVA hydrogels retained a higher amount of $\mathrm{KCl}$ compared with $\mathrm{NaCl}$, due to cation interaction with hydrogels.

From Fig. 9 it can be seen that the hydrogel samples dimensions evidenced an insignificant influence on the re-swelling hydrogels capacity (plotted \% of water from the hydrogel correspond to $1500 \mathrm{~min}$ of hydrogels re-immersion in water).

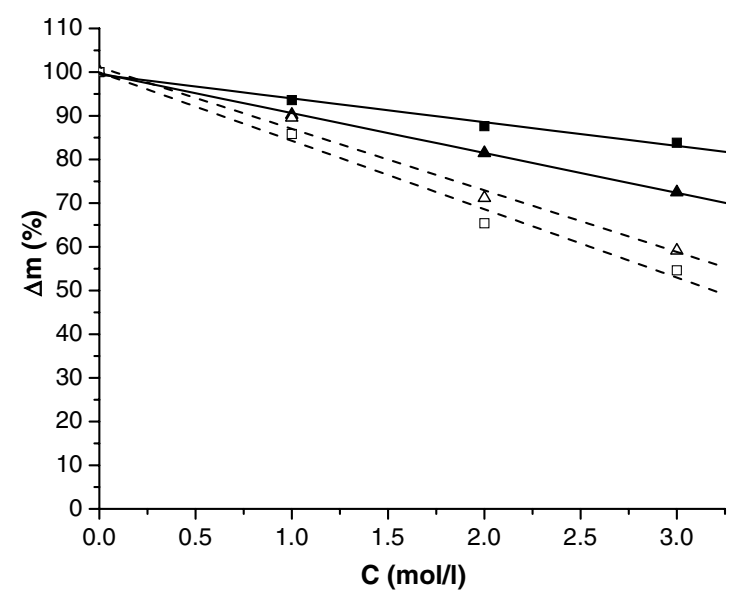

Fig. 8. Variation of the amount of water from PVA-HG, as a function of the electrolyte solution concentration, at their immersion in the electrolytes solutions: $(\triangle) \mathrm{NaCl}$; $(\square) \mathrm{KCl}$, and at the re-immersion in water of the shrunk hydrogels initially immersed in: (ם) $\mathrm{NaCl}$ solutions and $(\boldsymbol{\Delta}) \mathrm{KCl}$ solutions.

Table 3

Retained salt amount by the PVA HG sample, as a function of initial salt solution concentration and electrolyte type

\begin{tabular}{lll}
\hline Salt type & Salt concentration $(\mathrm{M})$ & Retained salt by $\mathrm{HG}(\mathrm{M})$ \\
\hline $\mathrm{KCl}$ & 3 & 1.78 \\
& 2 & 1.2 \\
& 1 & 0.58 \\
$\mathrm{NaCl}$ & 3 & 1.27 \\
& 2 & 0.9 \\
& 1 & 0.51 \\
\hline
\end{tabular}

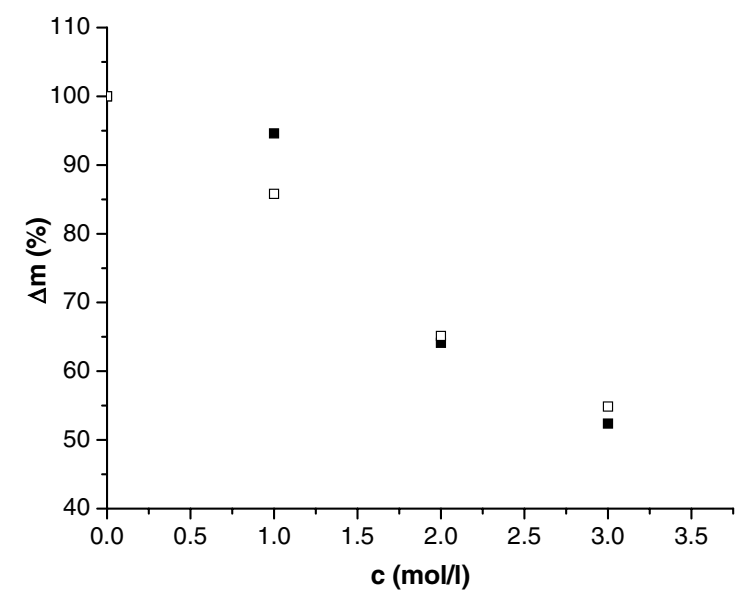

Fig. 9. The influence of the hydrogel samples dimensions on the re-swelling process, for hydrogels initially contracted in $\mathrm{KCl}$ solutions with different concentrations: (ם) type I; ( $\square$ ) type II.

\section{Conclusions}

Sorption and desorption of water in, respectively from PVA 90-98 hydrogels, obtained by repeated cycles of freezing and thawing, in the presence of concentrated $\mathrm{NaCl}$ and $\mathrm{KCl}$ aqueous solutions, have been studied.

It was evidenced that PVA-HG-s exhibit a mechanical active behaviour, shrinking in the presence of electrolytes and swelling in the presence of water.

The two processes (sorption and desorption of water) are not completely reversible, in only one step, due to the difference between the $\mathrm{NaCl}$ and $\mathrm{KCl}$ retention in the hydrogels matrix.

The experimental results show that the $\mathrm{K}^{+}$ions could be stronger retained in the PVA-HG structure, compared by $\mathrm{Na}^{+}$ions. As consequence, in presence of $\mathrm{KCl}$ solutions a higher amount of water has been eliminated from the hydrogel (mainly bonded and weakly bonded water).

It has been determined that higher hydrogel mass losses have been obtained for higher electrolyte concentration, for higher contact periods between hydrogel and electrolyte solution and by immersing the PVA-HG in $\mathrm{KCl}$ solutions comparatively with immersion in $\mathrm{NaCl}$ solutions.

The hydrogel mass losses are accompanied by hydrogels volume and density changes.

The $\mathrm{NaCl}$ and $\mathrm{KCl}$ could be eliminated completely from PVA HG-s by extraction with distilled water, in many steps. So, the same membrane, could be used more times on separation processes if more 
desorption steps are applied between the diffusion experiments.

The experimental data evidenced a non-Fickian water diffusion from the PVA swollen gels in the presence of $\mathrm{NaCl}$ and $\mathrm{KCl}$. Due to the property of $\mathrm{K}^{+}$ions to be $\mathrm{H}$-bonds cracker, the water diffusion from the PVA hydrogels could be better described by the molecular relaxation model $(n>0.5$ and dependent on $\mathrm{K}^{+}$ions concentration). In the presence of $\mathrm{Na}^{+}$ions, water diffusion from PVA gels could be closer to Fickian mechanism $(n \cong 0.6$ and independent on $\mathrm{Na}^{+}$concentration).

It could be concluded that the water elimination from PVA swollen hydrogels is strongly influenced by the cations nature, not only from kinetically and thermodynamically point of view, but also from that of the mechanism.

The obtained results are important for the quantifying of the tested salts diffusion through PVA 9098-HG membranes, for determining the capacity of PVA-HG to be loaded with different salts, to explain the influence of these salts presence in the diffusion of drugs or other active substances through PVA-HG membranes that are very similar with the human body cellular membranes and to manage the cells growing on PVA HG-s in nutrient environment (that usual contain $\mathrm{Na}^{+}$and $\mathrm{K}^{+}$ions).

\section{References}

[1] Nagash HJ, Okay O. Formation and structure of polyacrylamide gels. J Appl Polym Sci 1996;60:971-9.

[2] de Rossi D, Kajiwara K, Osada Y, Yamauchi A. Polymer gels. New York: Plenum Press; 1991.

[3] Guilherme MR, da Silva R, Rubira AF, Geuskens G, Muniz EC. Thermo-sensitive hydrogels membranes from PAAm networks and entangled PNIPAAm: effect of temperature, cross-linking and PNIPAAm contents on the water uptake and permeability. React Funct Polym 2004;61:233-43.

[4] Geever LM, Devine DM, Nugent MJD, Kennedy JE, Lyons JG, Higginbotham CL. The synthesis, characterization, phase behaviour and swelling of temperature sensitive physically cross linked poly(1-vinyl-2-pyrrolidinone)/poly( $N$-isopropylacrylamide) hydrogels. Eur Polym J 2006;42: 69-80.

[5] Zang X-Z, Ren-Xi Z. Novel synthesis of temperaturesensitive $\operatorname{poly}(N$-isopropylacrylamide) hydrogel with fast deswelling rate. Eur Polym J 2000;36:643-5.

[6] Hoare T, Pelton R. Highly $\mathrm{pH}$ and temperature responsive microgels functionalized with vinylacetic acid. Macromolecules 2004;37:2544-50.

[7] Suzuki A. Phase-transition in polymer gels induced by visible-light. Nature 1990;346:345-7.

[8] Muta H, Miwa M, Satoh M. Ion-specific swelling of hydrophilic polymer gels. Polymer 2001;42:6313-6.
[9] Philippova OE, Pieper TG, Sitnikova NL, Starodoubtsev SG, Khokhlov AR, Kilian HG. Solvent-specific swelling behavior of poly(allylamine) gel. Macromolecules 1995;28:3925.

[10] Paţachia S. Blends based on poly(vinyl alcohol) and the products based on this polymer. In: Vasile C, Kulshreshtha AK, editors. Handbook of polymer blends and composites. England: RAPRA Technology Ltd; 2003. p. 288-365.

[11] Paţachia S, Corboş C. Study on obtaining poly(vinyl alcohol) hydrogel. Bull. the "Transilvania" Univ. Braşov 2002;9(44) [New Series, Series B].

[12] Hassan CM, Peppas NA. Structure and applications of poly(vinyl alcohol) hydrogels produced by conventional crosslinking or by freezing/thawing methods. Adv Polym Sci 2000;153:37-65.

[13] Hernandez R, Sarafian A, Lopez D, Mijangos C. Viscoelastic properties of poly(vinylic alcohol) hydrogels and ferrogels obtained through freezing-thawing cycles. Polymer 2004; 46:5543-9.

[14] Hennink WE, van Nostrum CF. Novel crosslinking methods to design hydrogels. Adv Drug Deliv Rev 2002;54:13-36.

[15] Oh HJ, Kim SH, Baek JY, Seong GH, Lee SH. Hydrodynamic micro-encapsulation of aqueous fluids and cells via "on the fly" photopolymerization. J Micromech Microeng 2006;16:285-91.

[16] Lobo VMM, Valente AJM, Polishchuk AYa, Geuskens G. Transport of non-asociated electrolytes in acrylamide hydrogels. J Mol Liquids 2001;94:179-92.

[17] Fei JQ, Gu LX. PVA/PAA thermo-crosslinking hydrogel fiber: preparation and $\mathrm{pH}$-sensitive properties in electrolyte solution. Eur Polym J 2002;38:1653-8.

[18] Szilagyi A, Zrinyi M. Temperature induced phase transition of interpenetrating polymer networks composed of poly(vinyl alcohol) and copolymers of $N$-isopropylacrylamide with acrylamide or 2-acrylamido-2-methylpropyl-sulfonic acid. Polymer 2005;46:10011-6.

[19] Chun HJ, Lee SB, Nam SY, Ryu SH, Jung SY, Shin SH, et al. Preparation and swelling behavior of thermally crosslinked poly(vinyl alcohol) and poly(acrylic acid) hydrogel. J Ind Eng Chem 2005;11:556-60.

[20] Chen H, Hsieh YL. Ultrafine hydrogel fibers with dual temperature- and pH-responsive swelling behaviours. J Polym Sci A: Polym Chem 2004;42:6331-9.

[21] Sharkawy AA, Klitzman B, Truskey GA, Reichert WM. Engineering the tissue which encapsulates subcutaneous implants. 1. Diffusion properties. J Biomed Mater Res 1997; 37:401-12.

[22] Kim SY, Lee YM. Drug release behavior of electrical responsive poly(vinyl alcohol)/poly(acrylic acid) IPN hydrogels under an electric stimulus. J Appl Polym Sci 1999; 74:1752-61.

[23] Seabra AB, de Oliveira MG. Poly(vinyl alcohol) and poly(vinyl pyrrolidone) blended films for local nitric oxide release. Biomaterials 2004;25(17):3773-82.

[24] Patil SD, Papadimitrakopoulos F, Burgess DJ. Dexamethasone-loaded poly(lactic-co-glycolic) acid microspheres/ poly(vinyl alcohol) hydrogel composite coatings for inflammation control. Diabetes Technology Therapeutics 2004; 6(6):887-97.

[25] Mandal TK, Bostanian LA, Graves RA, Chapman SR. Poly(D,L-lactide-co-glycolide) encapsulated poly(vinyl alco- 
hol) hydrogel as a drug delivery system. Pharm Res 2002; 19(11):1713-9.

[26] Galeska I, Kim T, Patil SD, Bhardwaj U, Chatttopadhyay D, Papadimitrakopoulos F, et al. Controlled release of dexamethasone from PLGA microspheres embedded within polyacid-containing PVA hydrogels. AAPS J 2005;07(01): E231-E240. doi:10.1208/aapsj070122.

[27] Jagur-Grodzinski J. Biomedical application of functional polymers. React Funct Polym 1999;39:99-138.

[28] Malafaya PB, Silva GA, Baran ET, Reis RL. Drug delivery therapies II. Strategies for delivering bone regenerating factors. Curr Opin Solid State Mater Sci 2002;6:297-312.

[29] Hennink WE, Jong SJ, Bos GW, Veldhuis TFJ, van Nostrum CF. Biodegradable dextran hydrogels crosslinked by stereocomplex formation for the controlled release of pharmaceutical proteins. Int J Pharmaceut 2004;277:99104.

[30] He L, Buckton G, Gaisford S. Evaluating the interactions and release parameters of various drugs from hydrogels. JPP 2005;57(Suppl.).

[31] Pearton M, Barrow, Gateley DC, Anstey A, Wilke N, Morrissey A, et al. Hydrogels based on PLGA-PEG-PLGA triblock co-polymers as sustained release reservoirs for the delivery of pDNA to microneedle treated human skin. JPP 2005;57(Suppl.).

[32] Zhang Y, Jiang M, Zhao J, Zhou J, Chen D. Hollow spheres from shell cross-linked, noncovalently connected micelles of carboxyl-terminated polybutadiene and poly(vinyl alcohol) in water. Macromolecules 2004;37:1537-43.

[33] Hoffman AS. Hydrogels for biomedical applications. Adv Drug Deliv Rev 2002;42:3-12.

[34] Anseth KS, Metters AT, Bryant SJ, Martens PJ, Elisseeff JH, Bowman CN. In situ forming degradable networks and their application in tissue engineering and drug delivery. J Controlled Release 2002;78:199-209.

[35] Lemoine D, Wauters F, Bouchend'homme S, Préat V. Preparation and characterization of alginate microspheres containing a model antigen. Int J Pharmaceut 1998;176: 9-19.

[36] Cheng EHY. Combination of hydrogel and liposomes as a responsive drug delivery system. PhDThesis, University of Toronto; 1997 [Copyright Erik Cheng].

[37] Kumar MR. Nano and microparticles as controlled drug delivery devices. J Pharm Pharmaceut Sci 2000;3(2):234-58.

[38] Capan Y, Jiang G, Giovagnoli S, Na KH, De Luca PP. Preparation and characterization of poly(D,L-lactide-co-glycolide) micro-spheres for controlled release of human growth hormone. AAPS Pharm Sci Technol 2003;4(2):28. Article.

[39] Willaert R, Baron G. Gel entrapment and micro-encapsulation: methods, applications and engineering principles. Rev Chem Eng 1996;12:5-205.

[40] Schmedlen RH, Masters KS, West GL. Photocrosslinkable polyvinyl alcohol hydrogels that can be modified with cell adhesion peptides for use in tissue engineering. Biomaterials 2002;23:4325-32.

[41] Bromberg LE, Ron ES. Temperature-responsive gels and thermogelling polymermatrices for protein and peptide delivery. Adv Drug Deliv Rev 1998;31:197-221.

[42] Mandal TA, Bostanian LA, Graves RA, Chapman SR. Poly(D,L-lactide-co-glycolide) encapsulated poly(vinyl alcohol) hydrogel as a drug delivery system. Pharmaceut Res 2002;19(11):1713-9.

[43] Kikuchi A, Suzuki K, Okabayashi O, Hoshino H, Kataoka K, Sakurai Y, et al. Glucose-sensing electrode coated with polymer complex gel containing phenylboronic acid. Anal Chem 1996;68:823-8. 